Michael J. Severin, Oliver Lammel, Wolfgang Meier, Manfred Aigner, Flame Stabilization Regimes of Lean Premixed Confined Jet Flames at Different Reynolds Numbers, 53rd AIAA/SAE/ASEE Joint Propulsion Conference Atlanta, GA, 10-12 July 2017.

The AIAA version of the paper is accessible at https://doi.org/10.2514/6.2017-4684

On the AIAA web page

https://www.aiaa.org the interested reader can find other material published by AIAA 


\title{
Flame Stabilization Regimes of Lean Premixed Confined Jet Flames at Different Reynolds Numbers
}

\author{
Michael Severin, Oliver Lammel’ Wolfgang Meierł Manfred Aigner ${ }^{\ddagger}$ \\ German Aerospace Center (DLR) \\ Institute of Combustion Technology \\ Pfaffenwaldring 38-40, 70569 Stuttgart, Germany
}

\begin{abstract}
A premixed confined jet flame was investigated experimentally at atmospheric conditions in an optically accessible combustion chamber. The fuel was methane and the air/methane mixture was preheated to $200^{\circ} \mathrm{C}$. The flame was operated in the lean region, from stoichiometry to blow-off. Furthermore, the jet exit velocity was varied from $1 \mathrm{~m} / \mathrm{s}$ to $300 \mathrm{~m} / \mathrm{s}$. Experiments were conducted for a free and a confined jet.

The investigation supports the understanding of jet-stabilized flames in gas turbine combustors, particularly FLOX ${ }^{\circledR}$ combustors, with the aim of a better insight into fundamental flow-flame interactions. It was found that confined jet flames could only be stabilized at either low or very high jet velocities, which led to a classification into two regimes, termed "high velocity regime" and "low velocity regime". These regimes correspond to a turbulent and a laminar nozzle inflow, respectively, and are separated from each other at laminar-turbulent transition, where no flame could be stabilized.

At selected conditions, high-speed $\mathrm{OH}^{*}$-chemiluminescence (CL) imaging and Particle Image Velocimetry (PIV) measurements have been applied to gain insight into the fundamentally different flame stabilization mechanisms.

While the low-velocity regime is stabilized by laminar flame propagation, OH*_CL results show a disrupted and highly dynamic flame for the high velocity regime, with events of auto-ignition and local flame extinction. PIV results indicate a fundamental change of the flow field at the gap between the two regimes. It is assumed that the high velocity flame stabilization regime is based on permanent autoignition of the jet flow by recirculating hot exhaust gas, but further experiments are needed to validate this assumption.
\end{abstract}

\section{Nomenclature}

$\begin{array}{llll}T & \text { Preheat temperature }[\mathrm{K}] & \nu & \text { Kinematic viscosity }\left[\mathrm{m}^{2} / \mathrm{s}\right] \\ v_{\text {jet }} & \text { Nominal bulk flow jet velocity }[\mathrm{m} / \mathrm{s}] & R e & \text { Reynolds number based on global scales } \\ \lambda & \text { Air excess ratio } & O & \text { Order of magnitude } \\ v & \text { Velocity }[\mathrm{m} / \mathrm{s}] & v^{\prime} & \text { Velocity fluctuation }[\mathrm{m} / \mathrm{s}] \\ D & \text { Nozzle diameter }[\mathrm{m}] & K a & \text { Karlowitz number based on flame thickness } \\ x, y, z & \text { Spatial coordinates }[\mathrm{mm}] & K a_{R} & \text { Karlowitz number based on inner reaction layer } \\ S_{L} & \text { Laminar flame speed }[\mathrm{m} / \mathrm{s}] & R e_{T} & \text { Reynolds number based on turbulent scales } \\ l_{F} & \text { Laminar flame thickness }[\mathrm{mm}] & & \\ l_{T} & \text { Turbulent integral lengthscale }[\mathrm{mm}] & & \\ t & \text { Time }[\mathrm{ms}] & & \\ \Delta t & \text { Relative time }[\mathrm{ms}] & & \end{array}$

\footnotetext{
* Research Associate, DLR, Institute of Combustion Technology, Stuttgart, Germany, michael.severin@dlr.de.

†Senior Scientist, DLR, Institute of Combustion Technology, Stuttgart, Germany.

$\ddagger$ Professor, DLR, Institute of Combustion Technology, Stuttgart, Germany.
} 


\section{Introduction}

Jet-stabilized flames provide a promising alternative to swirl-stabilized flames in gas turbine combustion and are currently examined with regard to the application in stationary gas turbines. ${ }^{1,2}$ They have been shown to operate reliably with low (single digit) pollutant emissions at a wide operational range of gas turbine relevant conditions. ${ }^{3}$ Furthermore, they qualify for an operation with a large variety of both gaseous and liquid fuels. ${ }^{1,4-6}$

Jet-stabilized flames are used in FLOX ${ }^{\circledR}$ gas turbine combustors, ${ }^{1,2,7}$ which consist of nozzles circularly arranged on the burner base plate. These nozzles feed partially premixed air and fuel into the combustion chamber at high velocity (e.g. $100 \mathrm{~m} / \mathrm{s}$ ). An example can be seen in figure 1 on the left hand side, showing a FLOX ${ }^{\circledR}$ combustor used in high pressure combustion tests. The emerging high momentum jets form a reversed flow region in the center of said circle, which feeds hot combustion products back to the jet roots. This recirculation zone is crucial for flame stabilization, since the velocities in the vicinity of the high momentum jets are typically much higher than turbulent flame speed. Furthermore, the entrainment and intense mixing of combustion products into the incoming fresh gas reduce pollutant formation by avoiding local peak temperatures.

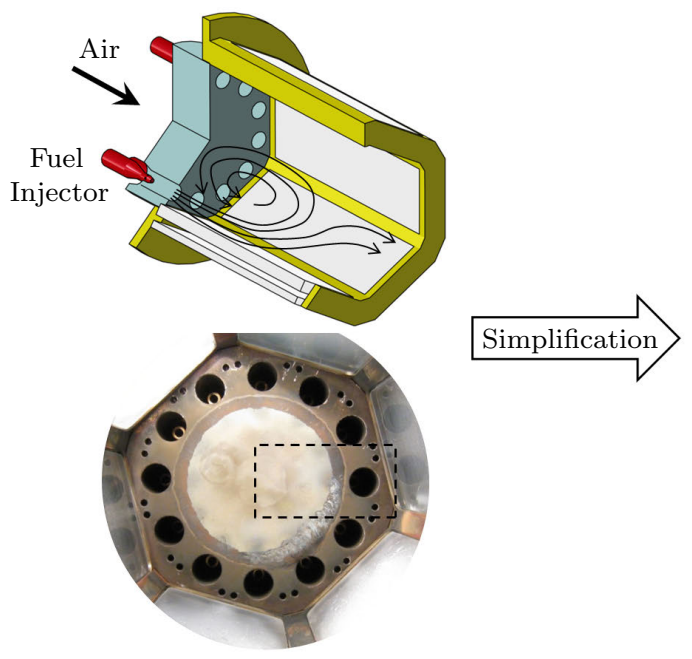

Full FLOX ${ }^{\circledR}$ Combustor

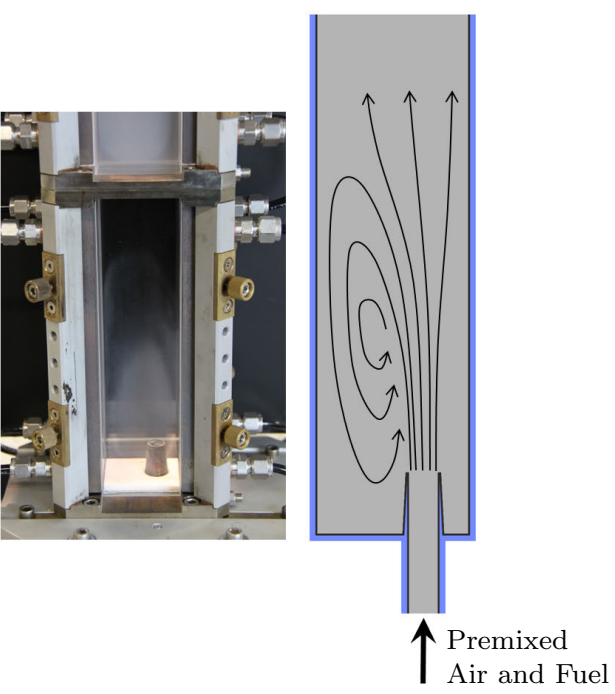

Confined Jet Model Combustor

Figure 1. Derivation of the confined jet model combustor: 8 Left side shows a full FLOX ${ }^{\circledR}$ combustor in a hexagonal combustion chamber. From this, a single nozzle is extracted as a section (dashed rectangle) and integrated into a rectangular combustion chamber. The lip at the nozzle is added to provide better access for optical diagnostics.

The processes of mixing and flame stabilization in a FLOX ${ }^{\circledR}$ combustor are not fully understood yet. $^{\text {a }}$ For example, it is still unclear whether autoignition or flame propagation plays the dominant role in this context. Also, the relationship between common (open) jet flames and recirculation-stabilized jet flames inside a FLOX ${ }^{\circledR}$ combustor is not well known to date.

In order to gain insight into these questions, a model combustor was designed, which exhibits a section of a full FLOX ${ }^{\circledR}$ combustor. This design is shown in figure 1. The model burner features a single off-centered nozzle, which is placed into a rectangular optically accessible combustion chamber. This setup is referred to as a confined jet flame and is used for lab-scale (atmospheric) tests. The off-centered arrangement allows for the formation of the characteristic recirculation zone on one side of the nozzle.

One particular question of interest for the present work is the influence of the jet exit velocity on the flames in FLOX ${ }^{\circledR}$ combustors. It was found in full burner system tests at high pressure, that a FLOX ${ }^{\circledR}$ burner is very load flexible, i.e. it can be operated at a wide range of air and fuel mass flows (meaning a wide

\footnotetext{
"It is emphasized that the term "FLOX" is only used as a description of the gas turbine burner type, i.e. "FLOX combustor", describing a circular arrangement of confined high momentum jet flames. In contrast, the term "FLOX combustion" should be avoided in this context, since the combustion regime is typically not flameless or MILD at gas turbine relevant conditions. ${ }^{2,7,9-11}$
} 
range of jet exit velocities) without a qualitative change of flame position and appearance in the combustion chamber. However, for low jet velocities (still much higher than flame speed) the FLOX ${ }^{\circledR}$ burner became unstable and finally the flame blew off, while no blow off was experienced at high jet velocities. ${ }^{12}$ This behavior is somewhat counter-intuitive for a premixed turbulent flame and is therefore examined further in the present lab-scale experiment of a single confined jet flame.

\section{Experimental Setup}

A schematic drawing of the model combustor can be seen in figure 2. The combustion chamber has a cross-section of $50 \mathrm{~mm} \times 40 \mathrm{~mm}$ and a length of $600 \mathrm{~mm}$. The combustion chamber exit is an open rectangle without any exhaust gas nozzle, and the burner is operated in a lab setup at atmospheric conditions. All four sides of the combustion chamber consist of quarz glass plates of length $200 \mathrm{~mm}$, which are held together by a water cooled metal frame. The burner base plate is made of a ceramic material and the protruding jet nozzle is a tapered stainless steel pipe.

The origin for the used coordinate system is placed at the center of the burner base plate. $x$ denotes the horizontal direction, $y$ the vertical (axial) direction, and $z$ the lateral direction in which the setup is symmetric. The circular nozzle has a diameter of $10 \mathrm{~mm}$ and is off-centered by $10 \mathrm{~mm}$ in $x$ direction. The nozzle lip protrudes into the combustion chamber by $20 \mathrm{~mm}$, providing a better access for optical diagnostics at the jet root.

The complete experimental setup is shown schematically in figure 3 . The combustion air is preheated and then mixed with the fuel. For the present work, pure methane $\left(\mathrm{CH}_{4}\right)$ was used as fuel. A thermocouple monitors the temperature of the preheated gas mixture roughly $100 \mathrm{~mm}$ upstream of the nozzle exit and feedback controls the air heater. For this work, the set temperature at the thermocouple position was always $473 \mathrm{~K}$. Different heating units had to be used for the variety of mass flows, and the order of heating and mixing was switched for smaller mass flows (this situation is depicted in figure 3$)$. To cover the wide range of investigated jet velocities $\left(v_{\text {jet }}=1-300 \mathrm{~m} / \mathrm{s}\right)$ and air excess ratios $(\lambda=1.0-1.6)$, a variety of massflow controllers had to be used for air and methane.

For a basic characterization and blow-off investigations, a mounted digital single-lens reflex (DSLR) camera was used to take photos of the flames. For a more detailed investigation of selected flames, a high speed camera (LaVision HighSpeedStar 6) together with a high speed image intensifier (LaVision HighSpeed IRO) and an optical bandpass filter $(310 \pm 20 \mathrm{~nm})$ was used to record the $\mathrm{OH}^{*}$ chemiluminescence (CL) signal at a frame rate of $10 \mathrm{kHz}$. The line-of-sight of this camera system was in $z$ direction, imaging the $x-y$ plane with the eccentric nozzle position. Note that the $\mathrm{OH}^{*} \mathrm{CL}$ signal is line-of-sight integrated, so the spatial information in $z$ is lost. To overcome this issue, a second high speed camera/intensifier/filter system was

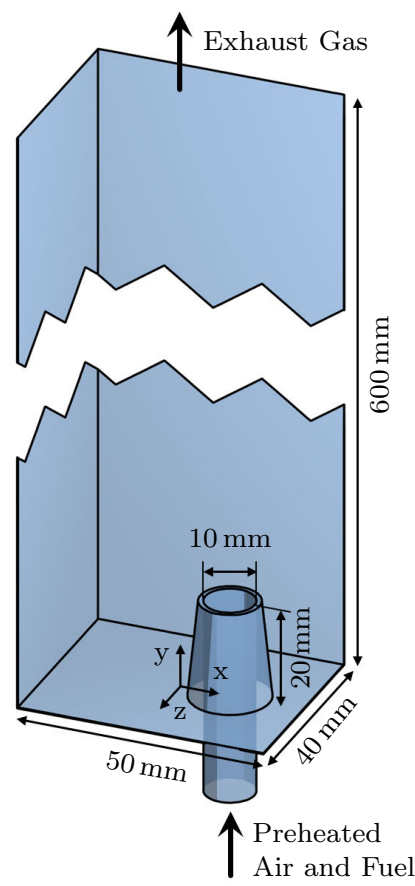

Figure 2. Model combustor with dimensions and used coordinate system. The nozzle axis is at $x=10 \mathrm{~mm}$ and $z=$ $0 \mathrm{~mm}$. used perpendicular to the first one, imaging the $y-z$ plane. This camera system was used simultaneously to the first one, so that the position of flame kernels could be tracked in all three dimensions (this second camera is not shown in figure 3 , it was placed at the beam dump position).

For the Particle Image Velocimetry (PIV) measurements, a small amount of air (about $5 \%$ of the total air flow) was fed through a fluidized bed seeder that seeded the flow with $\mathrm{TiO}_{2}$ particles. This seeding air was mixed into the main air at the same position as the fuel. The $\mathrm{TiO}_{2}$ particles have a diameter of about $1 \mu \mathrm{m}$, corresponding to a Stokes number of much less than unity, and thus follow the fluid streamlines with sufficient accuracy. ${ }^{13}$

The seeded flow inside the combustion chamber was illuminated by a high speed twin head diode-pumped Nd:YAG laser (EdgeWave InnoSlab IS200-2-LD), which was used at repetition rates of up to $5 \mathrm{kHz}$. The laser beam was formed into a sheet with a set of cylindrical lenses, resulting in a sheet of $120 \mathrm{~mm}$ height with a thickness of $<1 \mathrm{~mm}$. The laser sheet was adjusted to match the symmetry plane of the combustor at $z=0 \mathrm{~mm}$. The double pulse separation time was adjusted corresponding to the maximum expected flow velocities and was in the range of $20-800 \mu \mathrm{s}$. 


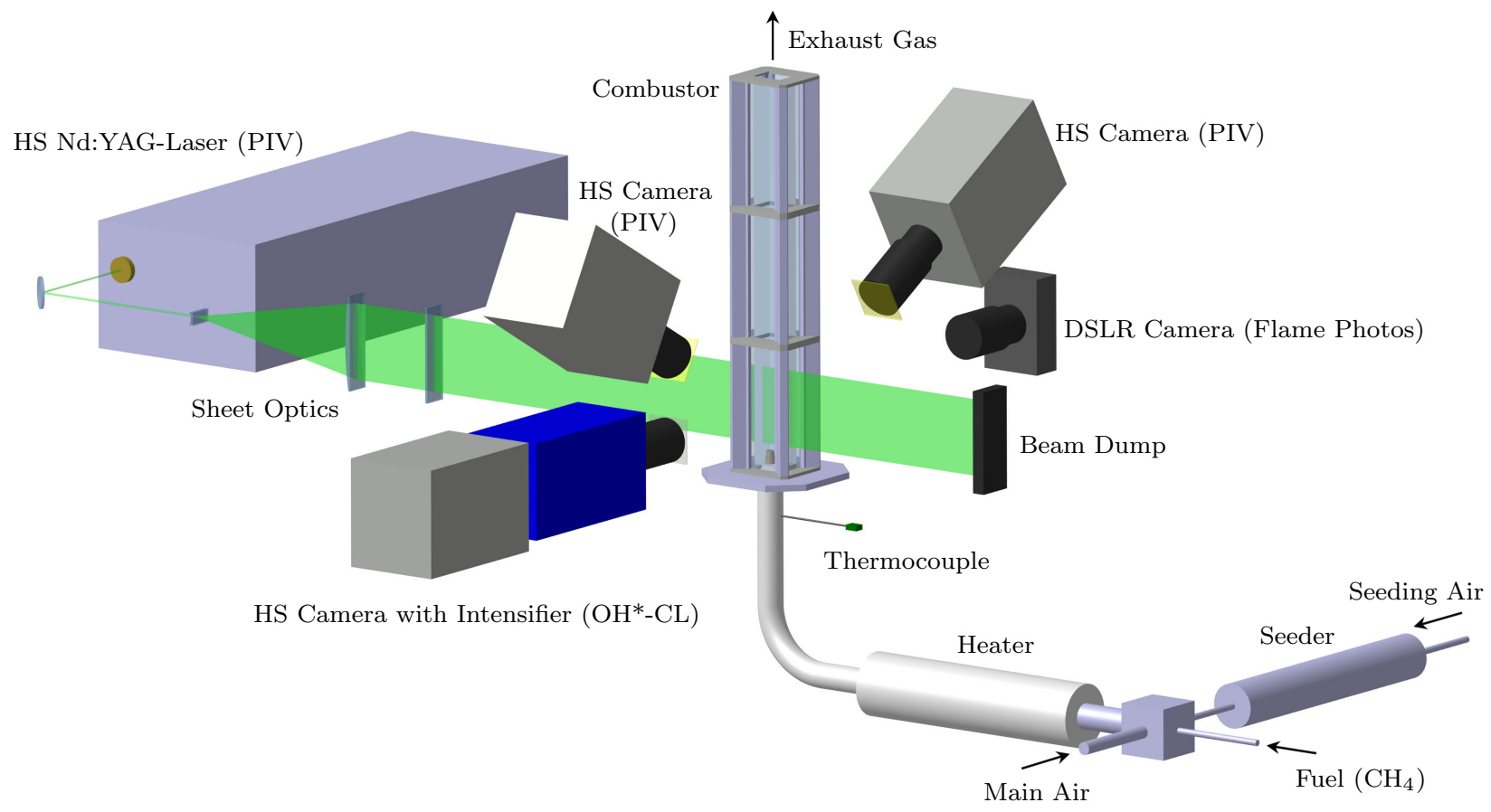

Figure 3. Schematic experimental setup. A second high-speed (HS) camera with intensifier was placed at the beam dump position for the non-simultaneous $\mathrm{OH}^{*}$-CL measurements.

Two high speed cameras (LaVision HighSpeedStar 8), equipped with an optical bandpass filter (532 \pm $5 \mathrm{~nm}$ ), were used in double frame mode to record the PIV images. The cameras were inclined at an angle of $30^{\circ}$ in order to perform stereoscopic PIV, resulting in all three velocity components. For the results presented in this work, PIV was only performed in the non-reacting flow, although the setup allows for the simultaneous application of PIV and $\mathrm{OH}^{*}$-CL in the reacting flow field.

At least 10000 double images were recorded for each operation point. The PIV images were processed with a commercial software (LaVision DaVis 8.3) on a single shot basis, and statistically analyzed in MatLab.

\section{Results}

\section{A. Characterization}

The model burner was lit at a typical operation point of $v_{\text {jet }}=90 \mathrm{~m} / \mathrm{s}$ and $\lambda=1.4$. While this $v_{\text {jet }}$ is close to a full burner system application value, the $\lambda$ for the model burner typically has to be lower than the real application value to achieve a stable flame, because of the surface to volume ratio and the significant heat loss in the optical combustion chamber. The preheat temperature was chosen as $473 \mathrm{~K}$ (which is also lower than in a full gas turbine system) in order to slow down chemical reactions with the expectation of a better ability to measure and resolve the processes of flame stabilization. The flame for this operation point is lifted from the nozzle exit by several centimeters and the flame appears widely distributed within the combustion chamber.

In a second step, the jet exit velocity $v_{\text {jet }}$ was varied while keeping $\lambda$ and $T$ constant. The velocity variation over more than two orders of magnitude required a frequent change of the experimental setup (mass flow controllers and preheating unit), so it was done in a staggered way. Photos of the resulting flames for this variation can be seen in figure 4 in the top row. All shown operation points were kept steady for at least $2 \mathrm{~min}$, before taking any measurements. For $\lambda=1.4$ the velocity could be lowered down to $50 \mathrm{~m} / \mathrm{s}$ without any major changes to the flame. Below $50 \mathrm{~m} / \mathrm{s}$, the flame became unstable (flickering) and finally blew off. This is marked as BO (blow-off) in figure 4. On the other hand, no limitations regarding the flame stability could be found with increasing jet velocity. The flame seemed even more stable the higher the velocity was (less flickering). In fact, $v_{\text {jet }}$ was ramped up to more than $300 \mathrm{~m} / \mathrm{s}$ with a stable flame, when the maximum of the lab's air supply was reached. 
Subsequently, the velocity variation was carried out for different values of $\lambda$ up to stoichiometry. The resulting flames can be seen in figure 4. Grey boxes depict operation points were the flame was stable but no measurement and photo have been taken. For all values of $\lambda$, the behavior towards higher velocities did not change and the flame became more stable while increasing $v_{\text {jet }}$. The stability towards lower velocities was increased with decreasing $\lambda$ and the burner could be operated stationary at $v_{\text {jet }}=20 \mathrm{~m} / \mathrm{s}$ and $10 \mathrm{~m} / \mathrm{s}$ for $\lambda=1.2$ and 1.0, respectively. However, there was always a minimum velocity at which the flame blew off and the flame never became attached to the nozzle. Furthermore, the flame lift-off height is remarkably constant (approx. $50-70 \mathrm{~mm}$ ) for all these cases and the flame length only changes within a factor of 2 $(100-200 \mathrm{~mm})$. It is therefore concluded that the flame stabilization mechanism is the same for all these operation conditions and the operational envelope depicted in figure 4 for the confined jet flame is referred to as the "high velocity regime".

After this regime was defined, the jet velocity was decreased even more. It was found that a flame could be stabilized again for $v_{\text {jet }}<4 \mathrm{~m} / \mathrm{s}$, depending on the air excess ratio $\lambda$. The associated photos of this so called "low velocity regime" are shown in figure 5.

Obviously the flames in this regime look fundamentally different and show a classical Bunsen-like flame: The flame shape is conical, the flames are attached to the nozzle rim and are more compact than in the high velocity regime. Even a distinct flame front can be seen in the photos.

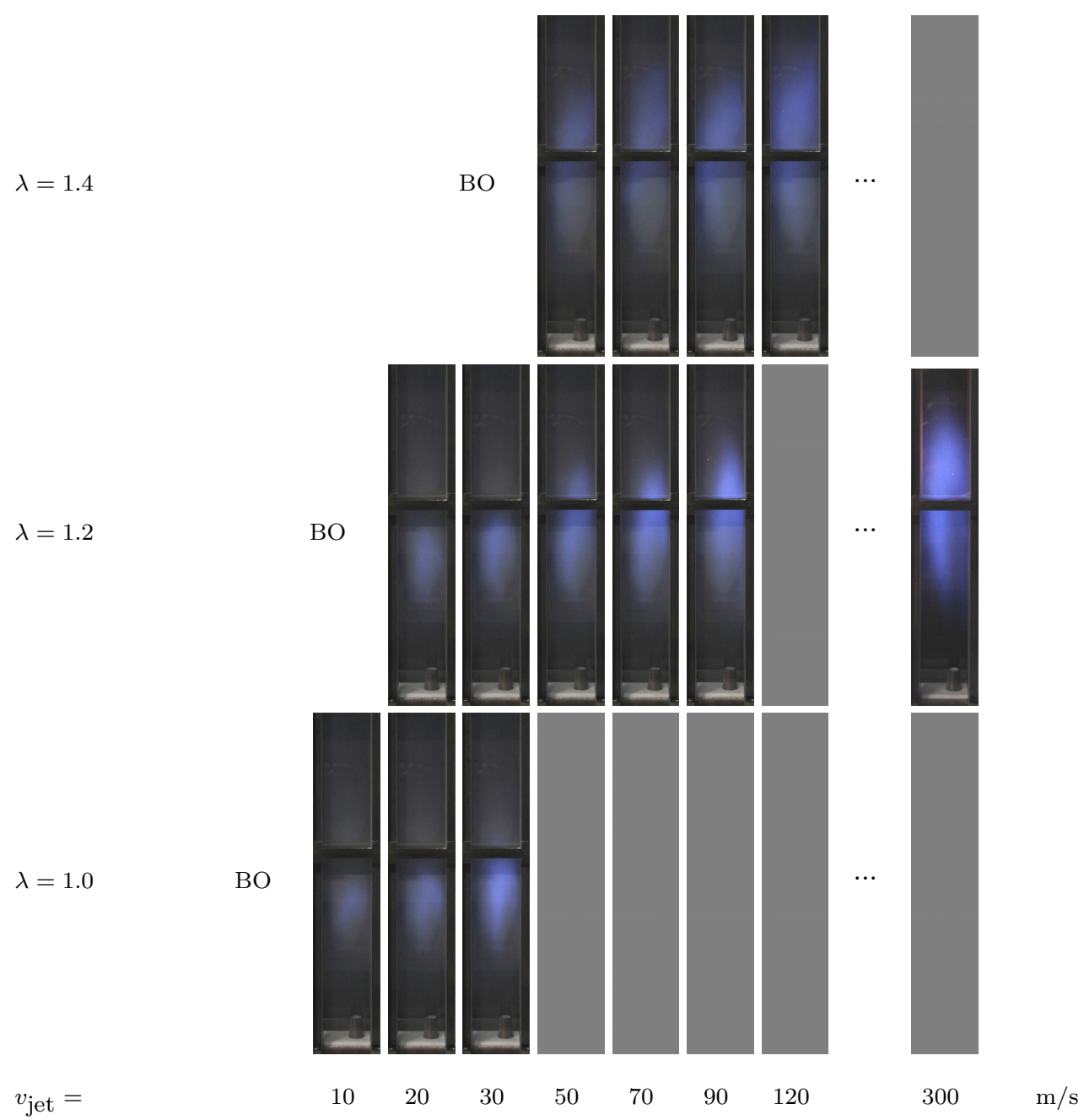

Figure 4. Photos of confined jet flames in the high velocity regime. No stability limit was found towards higher jet velocities. Grey boxes depict operation conditions where the flame was stable, but no measurements were conducted. 


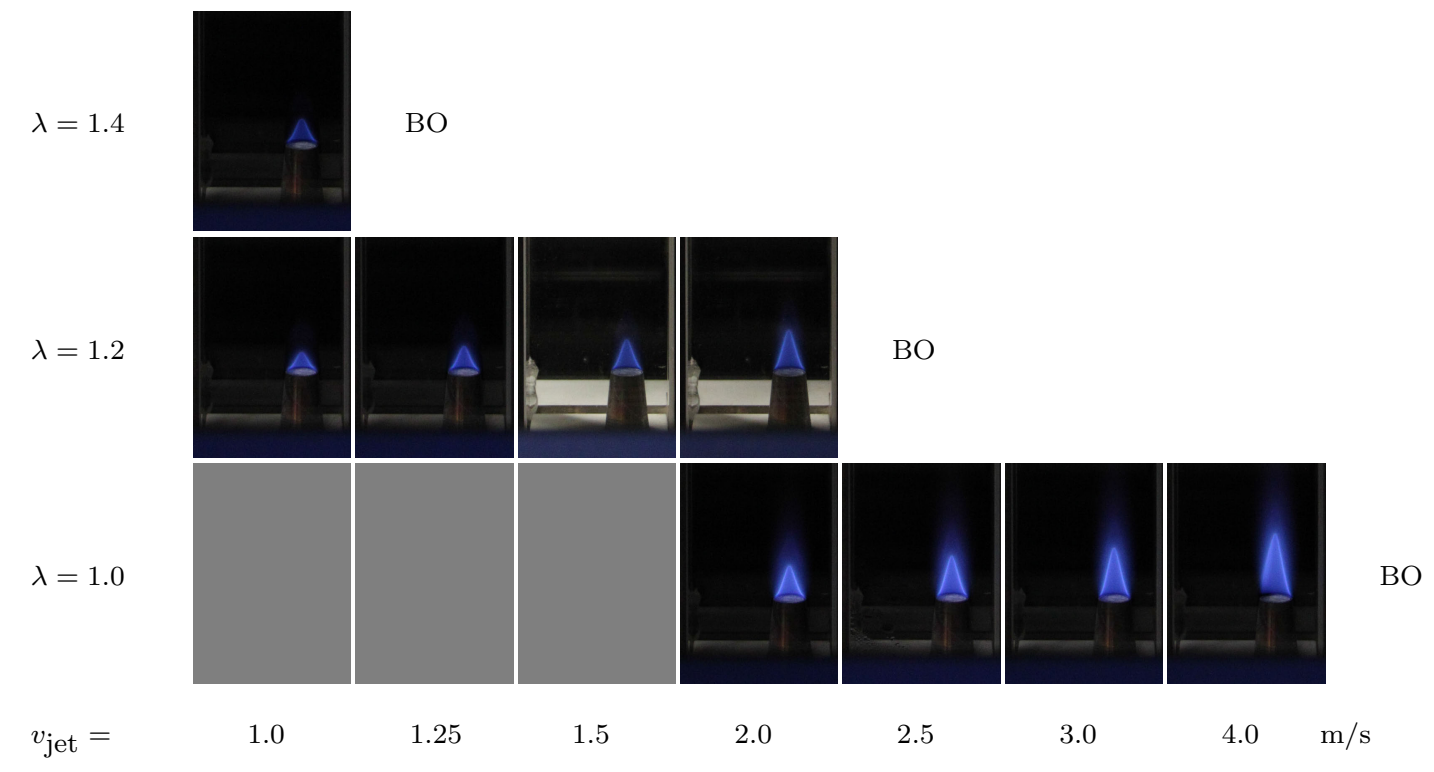

Figure 5. Photos of confined jet flames in the low velocity regime. Flashback occurs towards lower jet velocities. Grey boxes depict operation conditions where the flame was stable, but no measurements were conducted.

Furthermore, the influence of $v_{\text {jet }}$ on the flames is opposed, and shows a more intuitive behavior: The flame now becomes unstable and blows off when the velocity is increased (e.g. beyond $2 \mathrm{~m} / \mathrm{s}$ at $\lambda=1.2$ ). For a decrease of $v_{\text {jet }}$ below $1 \mathrm{~m} / \mathrm{s}$, flashback into the nozzle occurred. The flashback limits have not been examined in detail, since they are not the focus of this work. As in the high velocity regime, a $\lambda$ closer to stoichiometry allows for a larger variation of $v_{\text {jet}}$, in this case towards higher values. This effect is most likely due to higher flame speeds close to stoichiometry, which is visualized by a smaller flame front angle towards the nozzle exit plane (compare the two cases at $v_{\text {jet }}=2 \mathrm{~m} / \mathrm{s}$ ). This operational regime is referred to as the low velocity regime for the confined jet flame.

From the visual impression, it seems that the confined jet flame is independent from the recirculation zone for the low velocity regime, while it crucially depends on it for the high velocity regime. To prove this statement, the confinement (i.e. the combustion chamber) was removed, turning the setup into a free jet flame. No recirculation occurs in this case, since the jet can entrain fluid from the surrounding environment. The flames in the unconfined low velocity regime behave and look nearly identical to the low velocity regime of the confined jet. Pictures are therefore omitted here. The operational range is minimally extended, so that a flame could now be stabilized up to $v_{\text {jet }}=5 \mathrm{~m} / \mathrm{s}$ for $\lambda=1.0$.

In the high velocity regime, no flame could be stabilized without confinement. The flames could be ignited, but blew off immediately as soon as the ignition source was gone. This supports the assumption that the flame is fully dependent on the recirculation of hot exhaust gas in this regime.

\section{B. Blow-Off Investigation}

In a next step, the blow-off (BO) limits have been examined in more detail: First, the mentioned velocity variation was carried out at a constant $\lambda$, but slower and with finer steps towards the stability limits. The exact value of $v_{\text {jet }}$ where $\mathrm{BO}$ occurred was noted. Second, for a constant $v_{\text {jet }}$, the air excess ratio $\lambda$ was increased in the same slow stepwise way, until BO occurred. Both ways led to almost the same results and match the qualitative course seen in figures 4 and 5. The BO results are summarized and plotted versus a logarithmic scale of $v_{\text {jet }}$ in figure 6 .

Red and blue squares depict the measured BOs, while the red and blue lines show least-squares fits linear to $\log \left(v_{\text {jet }}\right)$. Grey symbols show results from a previous investigation, ${ }^{8}$ where the focus was not on the operational range. The figure shows both the high velocity and the low velocity regimes and summarizes the aforementioned trends. Although both regimes approach each other for $\lambda=1.0$, a small gap persists, where no flame could be stabilized and which could not be bridged. 


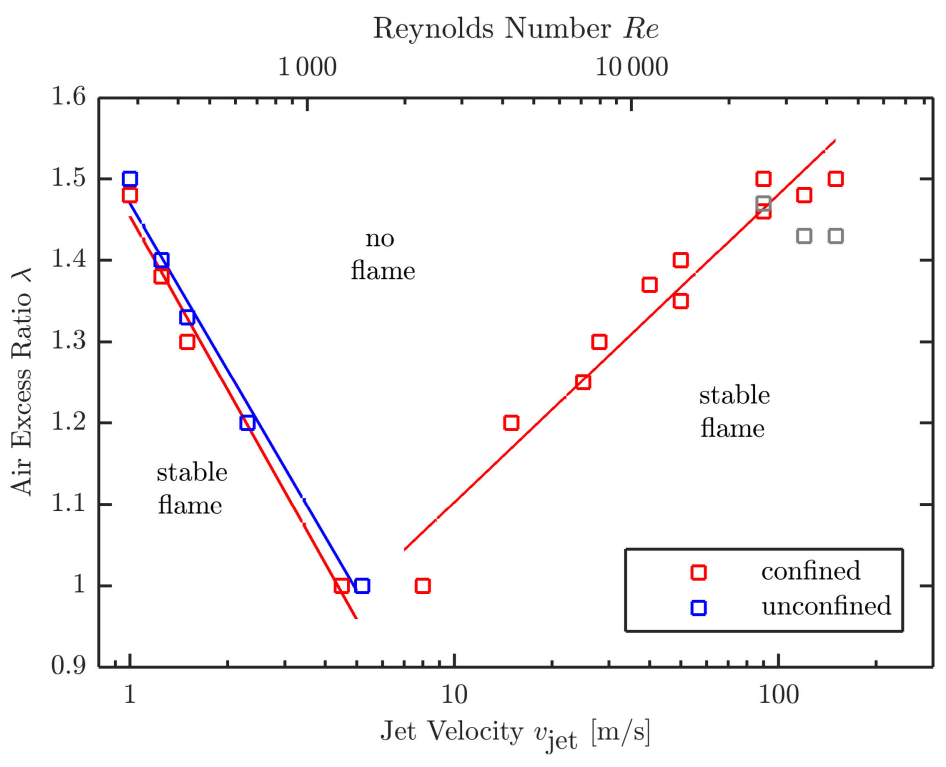

Figure 6. Blow off limits for confined and unconfined jet flame operation at $T=473 \mathrm{~K}$. Lines depict least squares fits. For the unconfined case, no high velocity operation regime exists. Grey symbols depict previous data from Lammel et al. ${ }^{8}$ for comparison.

Figure 6 is the main result of this work and shows fundamental differences to previously reported and well know stabilization diagrams for conventional burners. Wohl et al. ${ }^{14}$ reported a complete stabilization map of the unconfined Bunsen flame in 1949, which is reprinted by Law ${ }^{15}$ in his figure 8.6.10. Their plot qualitatively matches the course of the low velocity regime in figure 6 . They found a second regime of a lifted flame for very rich mixtures, which represents a lifted non-premixed turbulent jet flame. However, their regimes are connected and show the same trend of blowout towards higher velocities, with a slightly changed slope of the blowout line.

Amongst many others, Lefebvre and Ballal reported stabilization maps of gas turbine application swirl combustors, ${ }^{16}$ which show a loop of lean blowout towards higher $\lambda$, a rich extinction towards very low $\lambda$ (since gas turbine combustors are always confined) and a blowoff limit towards higher air mass flows, respectively flow velocities.

Keeping these known stabilization maps in mind, it is quite surprising to find a flame regime with a low velocity blowout limit (typically flashback is the low velocity limit) and an increasing stability with increasing flow velocities. Full burner system test indicate that this is a general stabilization phenomenon of FLOX ${ }^{\circledR}$ combustors (e.g. figure 5 in Seliger et al., ${ }^{17}$ although they do not mention the effect explicitly). An attempt of explanation of this phenomenon is made in section IV.

In the following, the corresponding Reynolds numbers $(R e)$ are taken into account. They are calculated based on the nozzle diameter $(D=10 \mathrm{~mm})$, the kinematic viscosity $\left(\nu=3.52 \cdot 10^{-5} \mathrm{~m}^{2} / \mathrm{s}\right)$ and the jet velocity $v_{\text {jet }}$ :

$$
R e=\frac{v_{\text {jet }} D}{\nu}
$$

The value for the kinematic viscosity was calculated for an atmospheric air/methane mixture with $\lambda=1.2$ and $T=473 \mathrm{~K}$. It changes only in the third significant digit $\left(3.51-3.53 \cdot 10^{-5} \mathrm{~m}^{2} / \mathrm{s}\right)$ for the whole range of investigated $\lambda \mathrm{s}$, which is neglected here.

These values lead to $R e=2841$ for $v_{\text {jet }}=10 \mathrm{~m} / \mathrm{s}$ for example, which can be scaled proportionally for other values of $v_{\text {jet }}$. This means $R e$ is in the order of $10^{2}$ for the low velocity regime corresponding to a laminar inflow, and in the order of $10^{4}$ for the high velocity regime corresponding to a turbulent inflow. Note that the terms laminar and turbulent only hold for the inflow conditions here. Most of the flow inside the combustion chamber is turbulent for all investigated cases, since a laminar jet at $R e \approx O\left(10^{2}\right)$ will always become turbulent after a certain axial distance from the nozzle exit. 
The gap around $v_{\text {jet }}=7-8 \mathrm{~m} / \mathrm{s}$ corresponds to $R e=2000-2300$. This matches exactly the region of the critical Reynolds number $R e_{\mathrm{cr}}{ }^{\mathrm{b}}$ for laminar-turbulent transition in a pipe flow. ${ }^{21}$ This means, a flame can be stabilized at a laminar and a turbulent inflow (low velcity and high velocity regime), but not at the transitional regime in between.

\section{Flow Field}

To gain insight into the changes of the overall flow field for the different regimes, particle image velocimetry (PIV) has been performed for a similar variation of $v_{\text {jet }}$. PIV measurements were done for a non-reacting air flow only, with the methane being replaced by additional air to reach the desired value of $v_{\text {jet. }}$. It is known from former studies, that the non-reacting flow field is altered only slightly by the heat addition of the flame in these kinds of combustors, ${ }^{8,22}$ and therefore holds as a good approximation. Figure 7 shows the average flow velocity fields for a variation of $v_{\text {jet }}$, calculated from 10000 instantaneous flow fields for each operation point. The velocity magnitude for each image is normalized by $v_{\text {jet }}$, to make them comparable in one color map.
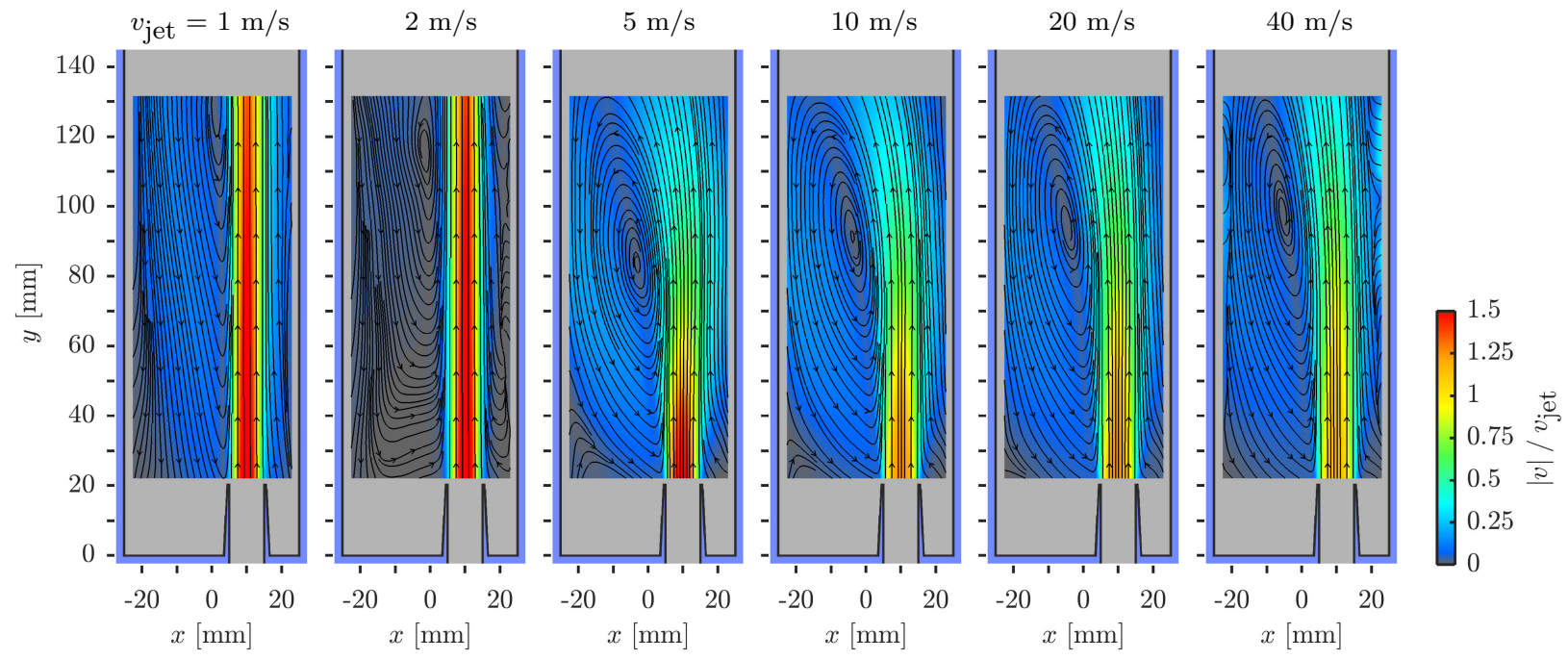

Figure 7. Averaged flow fields from non-reacting PIV measurements for different jet exit velocities. Streamlines show velocity direction, the color map shows the velocity magnitude. Velocity magnitude is normalized by the nominal jet exit velocity.

The flow fields of the high velocity regime $(10-40 \mathrm{~m} / \mathrm{s})$ show the typical features known from FLOX ${ }^{\circledR}$ combustors and confined jet flames: A decaying high-momentum jet and a prominent recirculation zone, which transports hot exhaust gas back to the jet root in the reacting flow field. The jet is bent towards the recirculation zone. Right at the nozzle exit, the maximum flow velocities exceed the bulk flow velocity only by $10-20 \%$ (orange color), which is an indication of a fully turbulent velocity profile exiting from the nozzle. The three flow fields in this regime are almost identical to each other and to previously reported flow fields at $v_{\text {jet }}=150 \mathrm{~m} / \mathrm{s}$, which can be found in figure 6 of the work by Lammel et al. ${ }^{8}$ The only visible change is the axial position of the recirculation vortex center, which slightly decreases with decreasing $v_{\text {jet }}$.

In the transitional regime at $v_{\text {jet }}=5 \mathrm{~m} / \mathrm{s}$, most of the average flow field shows the same characteristics as for the high velocity regime. The recirculation zone is still prominent, with the vortex center now being a little closer to the nozzle exit. The most significant change can be found in the velocity profile at the nozzle exit: The maximum velocity exceeds the bulk flow velocity by more than $50 \%$ (red color), which is a strong indication of a laminar parabolic velocity profile. The Reynolds number for this case is $R e=1420$, so a laminar flow profile at the nozzle exit is expected. The difference from a turbulent to a laminar velocity profile should also manifest itself in a much steeper velocity gradient at the jet boundary for the turbulent

\footnotetext{
${ }^{\mathrm{b}}$ The value $R e_{\mathrm{cr}} \approx 2300$, which is most found in literature today, can be traced back to measurements by J. Rotta around 1950. Latest experiments and direct numerical simulations suggest an updated value of $R e_{\mathrm{cr}} \approx 2040 \pm 10$, ${ }^{18-20}$ which matches the observed gap in figure 6 just as well.
} 
case. The PIV resolution is too coarse to resolve this difference, however it could be the reason for the reduced stability of the flame in this region, since a parabolic inflow profile diminishes shear and mixing drastically. However, the laminar jet obviously transitions to turbulence only a few centimeters from the nozzle exit, and from there on the flow field looks like in the high velocity case.

In the low velocity regime $(1-2 \mathrm{~m} / \mathrm{s})$ in figure 7 , the flow field changes completely: Although recirculation is still present, the relative velocity magnitudes of the back flow are smaller than in the high velocity regime. Furthermore, the extent of the recirculation zone (indicated by the vortex center) is much larger and seems to increase even further towards lower velocities. Together with the fact that the absolute velocities are much smaller in this region per se, this means that turnover times for the recirculating fluid are much higher for the low velocity regime. Since a permanent heat loss is present in the reacting flow field and therefore the temperature of the exhaust gas decreases while recirculating, this could be an explanation why flame stabilization based on recirculation brakes down for low velocities. This effect is already present within the high velocity regime, since the extent of the recirculation zone does not scale with $v_{\text {jet }}$. Moreover, it is likely that exhaust gas from a higher flame temperature (lower $\lambda$ ) can sustain a larger heat loss (slower turnover time) while still being able to stabilize a flame once entrained into the jet. This would explain the slope of the BO-line for the high velocity regime in figure 6.

The most striking difference in the low velocity regime is the penetration depth of the jet into the combustion chamber, which is much larger than for the turbulent jet in cases $5-40 \mathrm{~m} / \mathrm{s}$. This is caused by the laminar jet flow, which does not spread, has a much weaker entrainment of surrounding fluid and therefore hardly decays. The whole penetration depth is not covered by the field of view for those low velocity cases. Within the field of view, the jet does not bend towards the recirculation zone.

Since in the low velocity regime the absolute velocities are in the order of flame speeds for premixed methane-air flames, the flame can be stabilized by flame propagation, with no necessity for recirculating exhaust gas.

To get an impression of the unsteady nature of the flow field, figure 8 shows a representative instantaneous flow field for each velocity case. This looks almost identical to the average flow field for the very laminar case at $v_{\text {jet }}=1 \mathrm{~m} / \mathrm{s}$, i.e. no instantaneous fluctuations do occur. At $2 \mathrm{~m} / \mathrm{s}$, although the jet is still laminar, wrinkles start to occur in the reverse flow region. For the cases $5-40 \mathrm{~m} / \mathrm{s}$, the flow field is obviously fully turbulent (although the inflow at $5 \mathrm{~m} / \mathrm{s}$ with $R e=1420$ should still be laminar). The jet is wrinkled and wobbles back and forth. The recirculation zone in these cases consists of many small scale vortices, that only appear to be one large continuous backflow in the averaged flow field. With the increase in turbulence from $5 \mathrm{~m} / \mathrm{s}$ to $40 \mathrm{~m} / \mathrm{s}$, more vortices with smaller length scales occur at the jet boundary. However, vortices smaller than $2 \mathrm{~mm}$ are not resolved by the PIV method. The penetration depth of the jet appears to be smaller at $5 \mathrm{~m} / \mathrm{s}$ than for the higher velocities, and the jet seems to be the least homogeneous in this case.
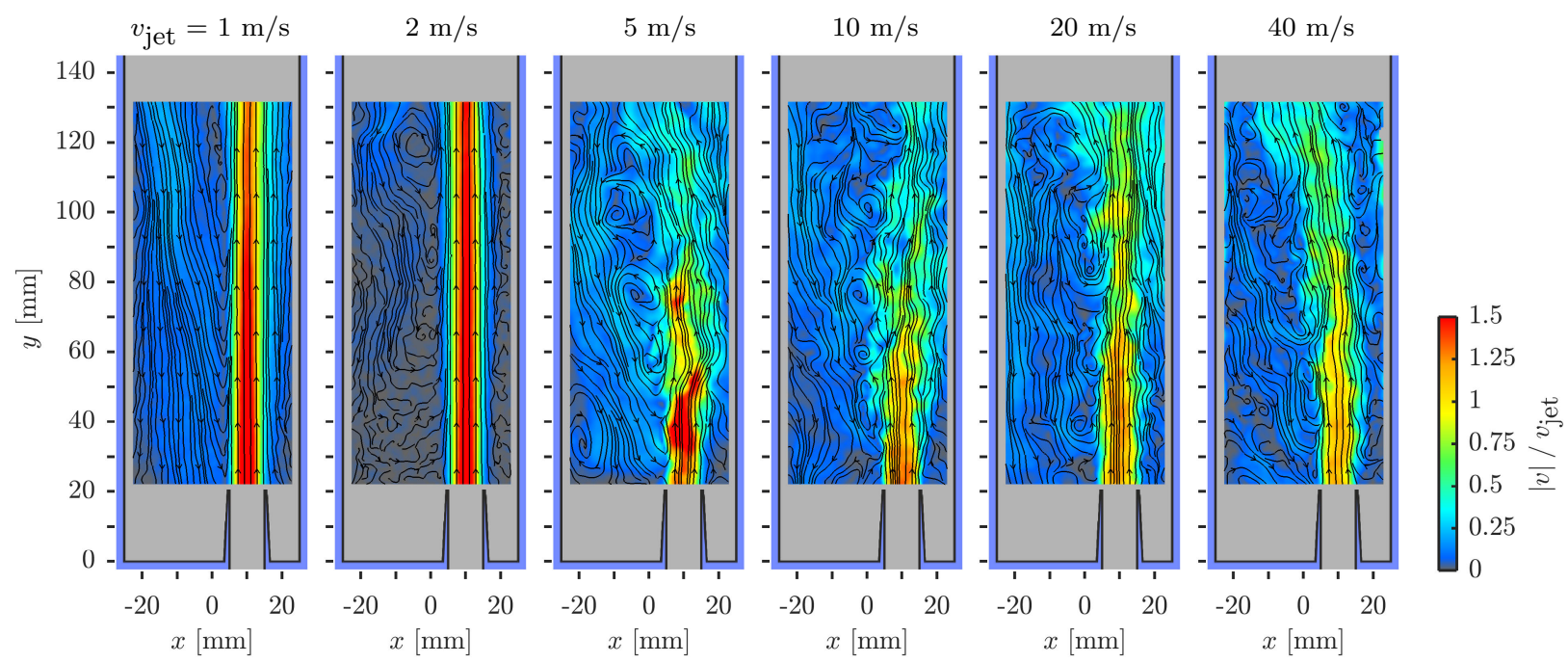

Figure 8. Representative instantaneous flow fields from non-reacting PIV measurements for different jet exit velocities. Velocity magnitude is normalized by the nominal jet exit velocity. 
The scale of the most prominent vortices (representing the integral length scale) does not change very much from $5 \mathrm{~m} / \mathrm{s}$ to $40 \mathrm{~m} / \mathrm{s}$, which is not surprising since an increase in Re mostly affects the smaller (Kolmogorov) scales of a turbulent flow, while the integral length scale is determined mostly by the geometry. If at all, the integral scale seems to decrease a little towards higher velocities. Taking into account the absolute velocities, this means that at a significantly lower velocity for $v_{\text {jet }}=5 \mathrm{~m} / \mathrm{s}$ together with a constant (or slightly increased) length scale of the vortices, the turnover time for these vortices (i.e. the characteristic time scale) increases drastically. This could again be a reason for the decreased flame stability in this case, since time-dependent heat loss and the loss of radicals through their relaxation towards equilibration inhibit the ignition of incoming premixed jet fluid, while the velocities are still higher than flame speed.

To display these impressions of the instantaneous fluctuations in a more statistical way, figure 9 shows the standard deviation of the 10000 single shot measurements of the flow field. The standard deviation is a measure for velocity fluctuations $v^{\prime}$, which are mostly due to turbulent motion and to some extent to intermittent flow states in the case of jet flapping. Like the velocity magnitudes, the standard deviation is normalized by the nominal jet exit velocity in each plot.
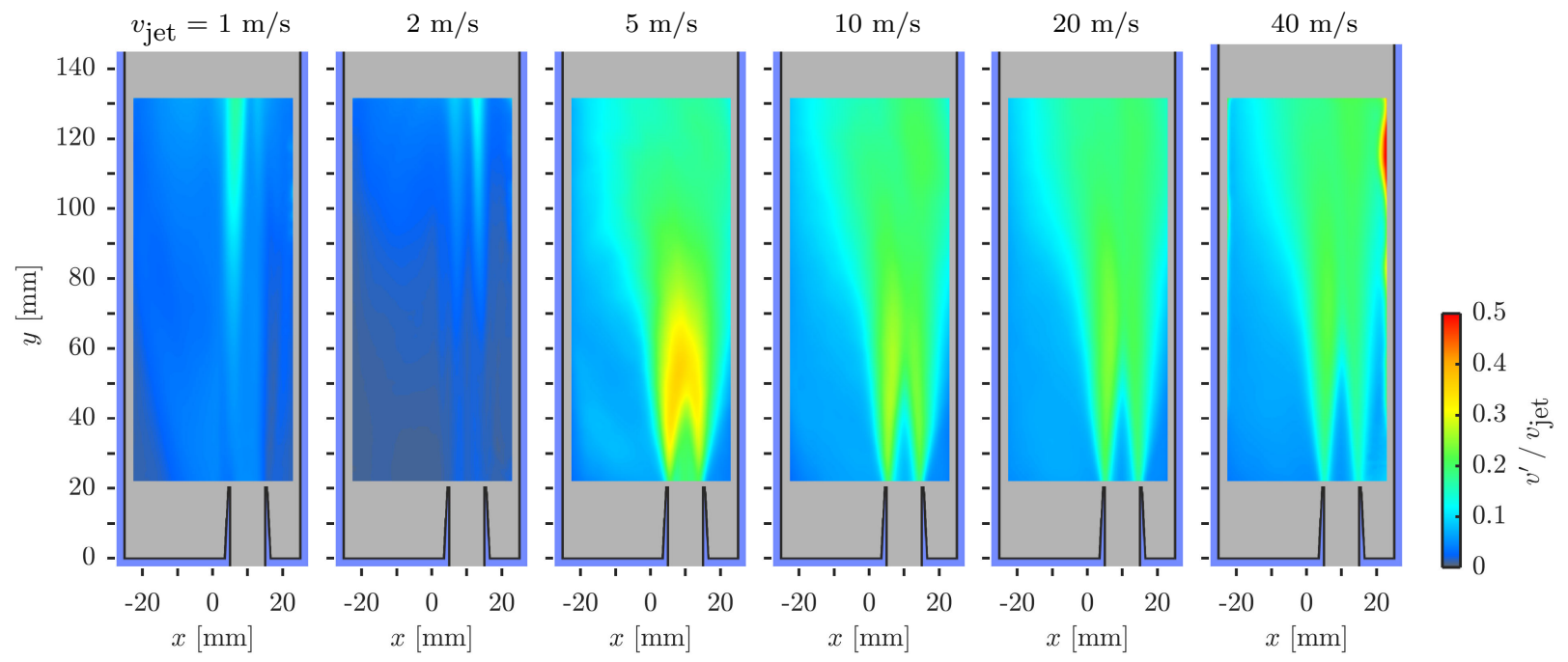

Figure 9. Standard deviation $v^{\prime}$ from non-reacting PIV measurements for different jet exit velocities, showing the areas of highest flow fluctuations. The standard deviation is normalized by the nominal jet exit velocity.

For the low velocity regime at $1 \mathrm{~m} / \mathrm{s}$ and $2 \mathrm{~m} / \mathrm{s}$, the fluctuations are fairly low, as expected from a laminar flow. For the high velocity regime, the strongest fluctations can be seen in the jet shear layers, which emerge from the nozzle rim, grow with downstream distance and finally merge once the jet is fully developed. The low fluctuation cone within the jet depicts the potential core region, which grows with increasing jet exit velocity. While the shear layers look very similar to each other in the cases $10-40 \mathrm{~m} / \mathrm{s}$, the shape and magnitude of the fluctuations is obviously different for the "no flame" regime at the case $5 \mathrm{~m} / \mathrm{s}$. Here, the relative fluctuation intensity is almost twice as high as for the other turbulent cases and the shear layers merge very close to the nozzle exit. A potential core is not visible at all. These strong fluctuations are most likely due to intermittent laminar-turbulent motion of the transitional jet in this case. This intermittent behavior could be another reason why a flame cannot be stabilized by recirculation in this case, since the crucial integral scale vortices are not permanently present.

\section{Flame Structure with $\mathrm{OH}^{*}$ Chemiluminescence}

In order to understand flame stabilization in the unsteady turbulent flow of the high velocity regime, $\mathrm{kHz}$ $\mathrm{OH}^{*}$-chemiluminescence (CL) measurements have been performed at selected cases in this regime, revealing the flame position, shape, and its temporal development. Shown here will be the case with $v_{\text {jet }}=20 \mathrm{~m} / \mathrm{s}$ and $\lambda=1.0$, since its relatively low velocities provide a good temporal resolution for the $\mathrm{kHz}$ diagnostics while not being too close to the blow off limit. The measurements have been performed from two sides simultaneously, resulting in an $x-y$ view (termed front view) and an $z-y$ view (termed side view). 

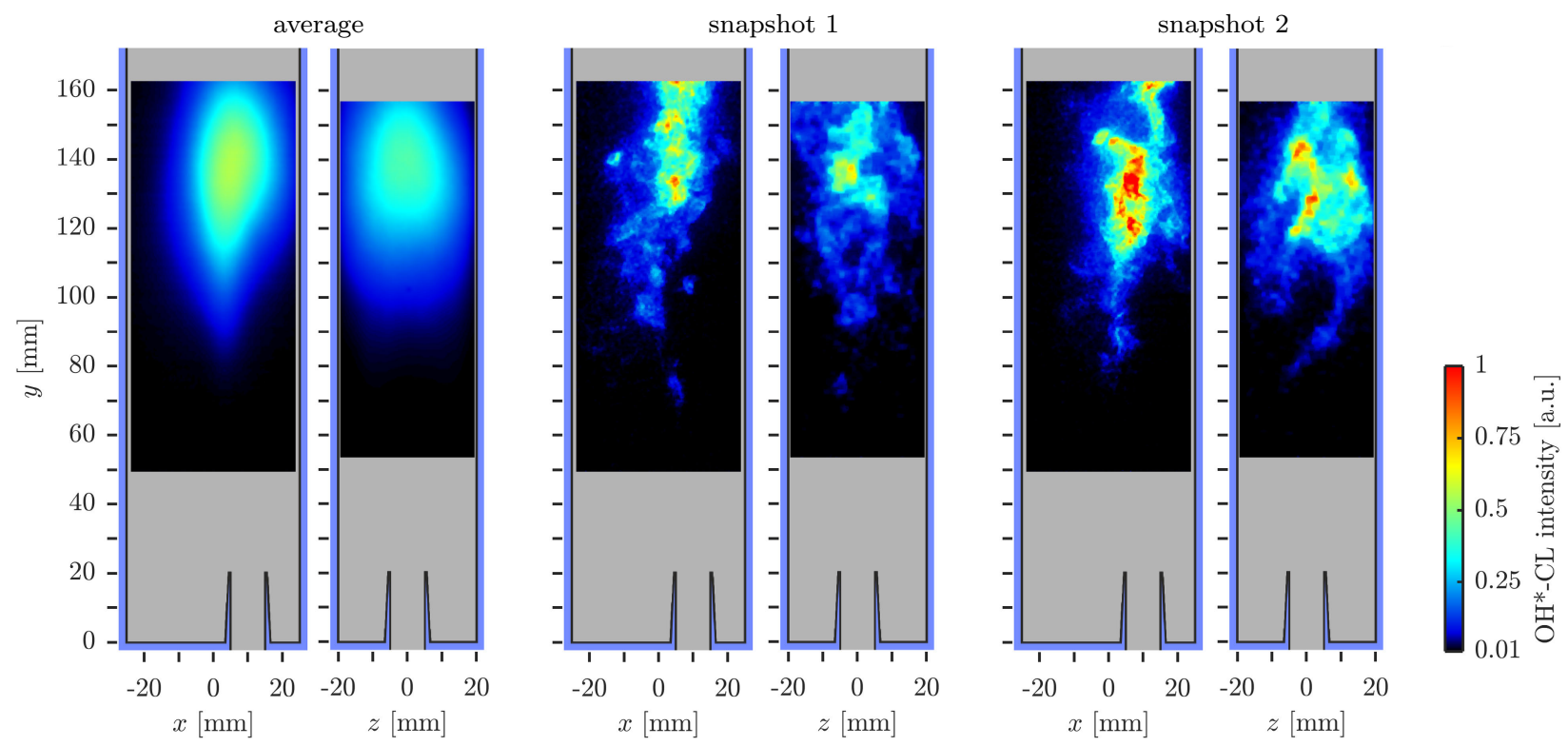

Figure 10. OH*-CL average (left) together with two representative instantaneous snapshots (right) for the high-velocity case $v_{\text {jet }}=20 \mathrm{~m} / \mathrm{s}$ and $\lambda=1.0$. Shown is both front- and sideview, respectively.

Figure 10 shows the average $\mathrm{OH}^{*}$-CL image for the selected case, together with two exemplary instantaneous measurements, each shown in both views. The average flame shape in the front view looks very similar to the luminosity photo in figure 4, which supports the statement that luminosity photos are an adequate way for a coarse characterization of flame position and shape in this type of combustor. While the flame is clearly asymmetric in the front view, it is nearly symmetric in the side view. According to these images, the lift-off height is approximately $60-70 \mathrm{~mm}$ (note that the nozzle rim is at $y=20 \mathrm{~mm}$ ). The flame looks smooth and distributed over a large volume.

This impression is different for the instantaneous images: The flame looks wrinkled, disrupted and highly turbulent. As for the flow field, the average image is not an appropriate choice to grasp the real characteristics of the flame structure. In both snapshots, most of the reaction happens at the downstream end of the field of view, while a flame root with lower intensity reaches upstream much closer to the nozzle exit. The flame is highly unsteady, with its position, extent and connectivity changing drastically over the whole measurement series (not shown here). Separated flame kernels and holes in the flame can be seen in snapshot 1. The flame edge appears to be sharper at the jet side than towards the recirculation side, where the flame dissipates into equilibrium. Furthermore, the flame structure is highly three-dimensional: In the sideview of snapshot 2, it can be seen that the flame root actually consists of two branches, one on the left and one on the right side of the jet. The branch on the right side (positive $z$ ) encompasses the jet and reaches into the center. This shows the difficulty for planar laser measurements in this flame (see section IV), since a planar measurement at the symmetry plane would interpret this branch as an isolated flame kernel.

The flame kernel upstream of the flame root in snapshot 1 could either be an event of autoignition or a remainder of a broken flame front. The classification into these oppositional processes is only possible if the temporal development is taken into account, which is the reason why the $\mathrm{OH}^{*}$-CL recording was done at a frame rate of $10 \mathrm{kHz}$. In the whole measurement series, both autoignition and local flame extinction events can be found to a similar extent.

To get an impression of these dynamics at the flame root, the lift-off height was identified for each single shot image and tracked over time. The lift-off height was defined as the lowest pixel location ( $y$-value) where the chemiluminenscence signal exceeds $4 \%$ of the global maximum. The threshold $4 \%$ corresponds to the onset of dark blue in the previous plots and was chosen as the lowest possible value which did not exhibit artifacts due to background radiation or intensifier noise. A representative section of the course of the lift-off height is shown in figure 11. Note that this height is the distance from the burner base plate and not from the nozzle exit. 


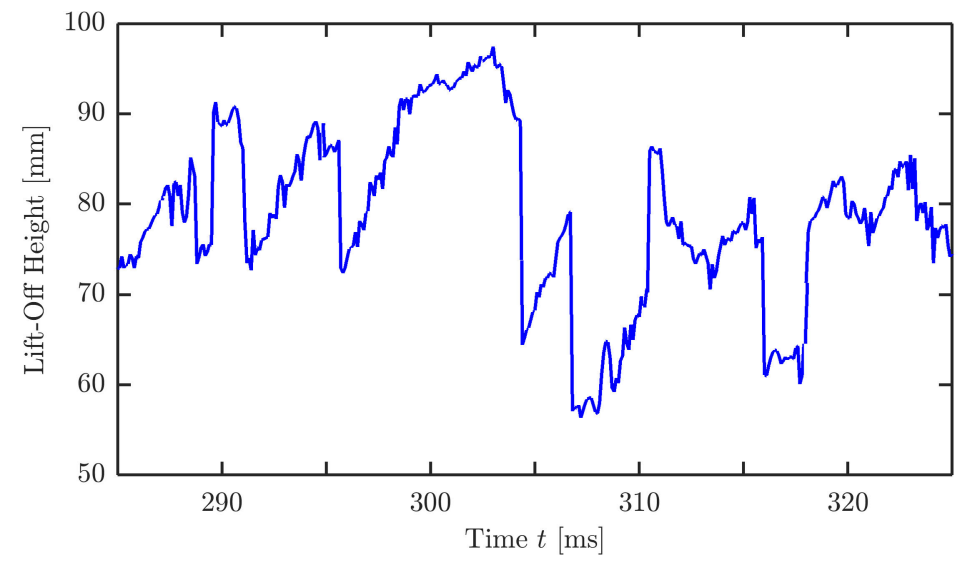

Figure 11. Temporal development of the lift-off height for case $v_{\text {jet }}=20 \mathrm{~m} / \mathrm{s}$ and $\lambda=1.0$.

The lift-off height is obviously highly fluctuating even within this short section of 40 ms and varies between $y=56 \mathrm{~mm}$ and $y=97 \mathrm{~mm}$. While most of the time the lift-off height is slowly rising (over several ms), it sometimes decreases within a very short period $<0.1 \mathrm{~ms}$. These jumps depict events of emerging ignition kernels. Such a behavior has been reported in literature on auto-ignition in the past and is usually referred to as the characteristic "saw-tooth" profile. ${ }^{23,24}$ It is a robust indication of consecutive auto-ignition events.

In the shown profile, also jumps of increasing lift-off height can be seen (at $t=289,311,318 \mathrm{~ms}$ ). These jumps on the other hand represent local flame extinction, either of a nascent ignition kernel or a disrupted portion of the flame.

An example of the temporal evolution of an autoignition event is shown as a sequence of OH*-CL images in figure 12. At $\Delta t=1 \mathrm{~ms}$ a small autoignition kernel appears, where no flame was present before. This is displayed by the white arrow in figure 12. The flame kernel is convected downstream and expands up to $5 \mathrm{~ms}$. At $\Delta t=6 \mathrm{~ms}$, the kernel is engulfed by the main flame and the situation is similar to the first frame again.

Note that for the sake of space, no sideviews are shown for this sequence here, although the observed
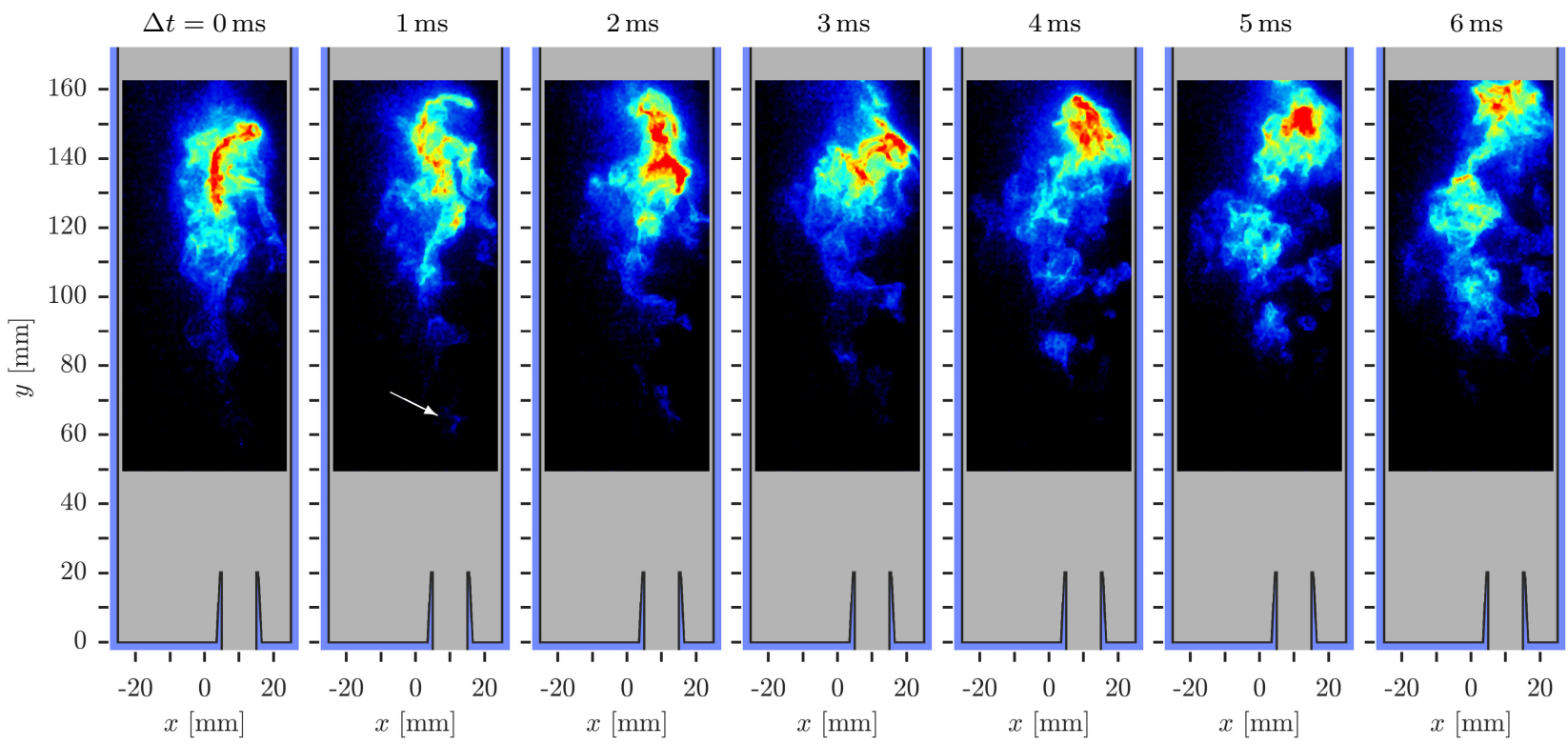

Figure 12. OH*-CL sequence, showing the development of an autoignition flame kernel. Only front view is shown. The color scale is the same as for the previous figure. Only every tenth image of the series is shown. 
flame kernel does show certain three-dimensional effects: The kernel actually originates at the side of the jet (at $(x, z) \approx(10,10))$ and wanders around the jet as it moves downstream. At $\Delta t=4 \mathrm{~ms}$, it has reached the symmetry plane and then spreads in $z$-direction, before it finally connects to the major part of the flame.

A Fourier analysis has been performed on the $\mathrm{OH}^{*}$-CL series to check if these autoignition events occur at a certain regularity. A prevailing frequency of $38 \mathrm{~Hz}$ was found in the region below the flame root. However, this frequency maximum is only slightly higher than the subsequent frequencies and the corresponding spectrum is rather broad, so a mostly random nature of this process is concluded.

\section{E. Classification into Premixed Turbulent Combustion Regimes}

To complete the picture of the different flame stabilization regimes, it is necessary to take a look at the characteristic chemical kinetic parameters, like laminar flame speeds. Calculations have been performed using the software Chemical Workbench 4.1 with embedded Cantera flame reactors. The used reaction mechanism was the GRI3.0 mechanism. ${ }^{25}$

The chemical kinetic calculations are independent of $v_{\text {jet }}$, therefore the only varied parameter is the air excess ratio $\lambda$. Table 1 shows the results for laminar flame speed $S_{L}$ and laminar flame thickness $l_{F}$ for the three inflow conditions $\lambda=1.0,1.2,1.4$. The laminar flame thickness was determined by the maximum temperature gradient criterion. As expected, laminar flame speed becomes slower for leaner mixtures, while the flame thickness increases slightly.

\begin{tabular}{lcc}
$\lambda$ & $S_{L}[\mathrm{~m} / \mathrm{s}]$ & $l_{F}[\mathrm{~mm}]$ \\
\hline 1.0 & 0.81 & 0.37 \\
1.2 & 0.68 & 0.41 \\
1.4 & 0.52 & 0.48
\end{tabular}

Table 1. Laminar flame speed $S_{L}$ and flame thickness $l_{F}$ for the three used air excess ratios $\lambda$ and constant preheat temperature $T=473 \mathrm{~K}$.

For the low-speed regime with $v_{\text {jet }}<5 \mathrm{~m} / \mathrm{s}$, these theoretical quantities are directly linked to the flame stabilization via laminar flame propagation and could be estimated from the conical flame shapes in figure 5 . The roughly determined flame angles from those photos match the calculated laminar flame speeds well, although the burner was not optimized for a homogeneous laminar bulk flow.

For the high-speed regime with $v_{\text {jet }}>8 \mathrm{~m} / \mathrm{s}$ the results in table 1 can be used as characteristic quantities, but do not have a direct physical meaning in combustion for several reasons: First, the flow in these cases is clearly turbulent, and therefore turbulent flame speeds would need to be considered. Second, the incoming jet is mixed with a certain amount of hot exhaust gas before it reaches the lifted flame, and therefore the thermochemical conditions of the unburned reactants differ from the pure inflow and are unknown. Third, as it was shown in the previous section, autoignition plays a significant role in this regime which makes flame speeds and thicknesses obsolete.

Nevertheless, laminar flame speed and laminar flame thickness are widely used as chemical reference quantities in premixed turbulent combustion research. They can be found in the definition of Damköhler numbers, Karlowitz numbers and the Borghi diagram, and will be used for the same purpose here.

In order to classify the investigated flames into the Borghi diagram, it is necessary to relate the characteristic chemical quantities to the characteristic turbulent flow quantities, i.e. fluctuation velocity $v^{\prime}$ and integral turbulent length scale $l_{T}$. While $v^{\prime}$ is already shown in figure 9 , the integral length scale had to be calculated in a seperate manner: Following Pope $^{26}$ (equations (6.41) and (6.47)), the longitudinal length scale $L_{11}$ was chosen for $l_{T}$ and calculated for each location in the flow field by averaging the spatial twopoint correlation of $v_{y}$ in $y$-direction over time and integrating the resulting correlation function up to the first zero crossing.

The results of this calculation show quite constant values of $l_{T}$ for the measured cases of $v_{\text {jet }}=1-40 \mathrm{~m} / \mathrm{s}$, which matches the know fact that the integral (large) length scales of turbulence are mainly dependent on geometry and almost independent of $R e$ (while the smaller Kolmogorov scales decrease with increasing $R e$ ). The fluctuations $v^{\prime}$ on the other hand scale almost linearly with $v_{\text {jet }}$, as shown by the constant ratio of $v^{\prime} / v_{\text {jet }}$ in figure 9 . 


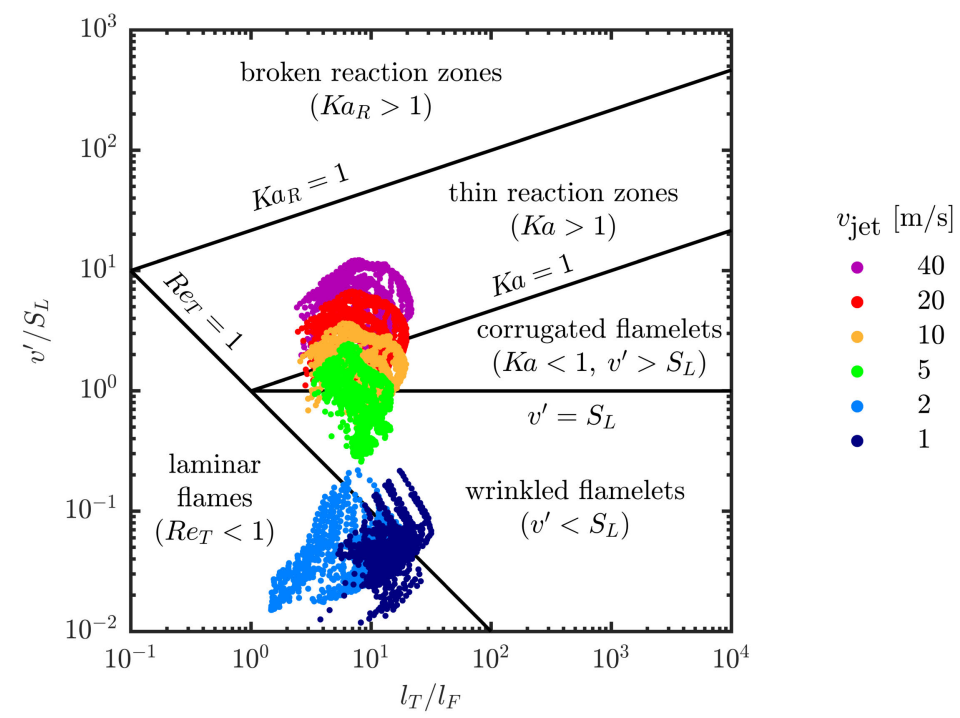

Figure 13. Turbulent premixed regime diagram by Borghi ${ }^{27}$ in the presentation of Peters ${ }^{28}$ with colored scattered data from the PIV-measurements (turbulence quantities $v^{\prime}$ and $l_{T}$ ) and the chemical kinetics calculations $\left(S_{L}\right.$ and $\left.l_{F}\right)$.

The result of the pointwise evaluation of $v^{\prime} / S_{L}$ and $l_{T} / l_{F}$ for each measured jet velocity is plotted in the Borghi diagram in figure 13. For each $v_{\text {jet }}$ both ratios are scattered over almost an order of magnitude. However, the general trends are clearly visible and the data results in two separated regimes:

The stably burning cases $v_{\text {jet }}=1-2 \mathrm{~m} / \mathrm{s}$ fall into the laminar flame region $R e_{T}<1$, as expected, since $v^{\prime}$ is close to zero here. The increasing integral length scales for the slowest case $v_{\text {jet }}=1 \mathrm{~m} / \mathrm{s} \mathrm{move} \mathrm{this} \mathrm{data}$ cloud close to the limit of $R e_{T}=1$. However, the definition of a turbulent length scale becomes questionable for this very laminar case (correlating zero to zero) and the increasing values of $l_{T}$ are probably erroneous due to the finite spatial resolution of the PIV technique.

The turbulent cases $v_{\text {jet }} \geq 5 \mathrm{~m} / \mathrm{s}$ show similar values of $l_{T} / l_{F}$ as the laminar cases, while $v^{\prime} / S_{L}$ is much higher. These data points are all located in the premixed turbulent flames regime but span multiple regions of $K a$ (and $D a$ ), namely the wrinkled flamelets, the corrugated flamelets and the thin reaction zones regimes. The high velocity cases of $v_{\text {jet }}>100 \mathrm{~m} / \mathrm{s}$ probably even fall into the broken reaction zones regime of $K a_{R}>1$. Note that different regimes of turbulent premixed combustion in the Borghi diagram do not necessarily refer to different regimes of flame stabilization. As the results from the previous sections suggest, flame stabilization in the high velocity regime is always based on autoignition at the flame root, while the structure of the following downstream flame propagation can then depend on the respective Borghi diagram regime.

Furthermore, no conclusion can be drawn from the Borghi diagram about the flame stabilization gap around $v_{\text {jet }} \approx 5 \mathrm{~m} / \mathrm{s}$, due to the same reason that the Borghi diagram provides no information about flame stabilization.

\section{Conclusions and Outlook}

Premixed methane/air flames have been investigated in an eccentric confined jet setup. The investigated confined jet flame can be stabilized in two different regimes: At a laminar and a turbulent inflow, but not in the transitional regime in between. Flame photos, PIV results and $\mathrm{OH}^{*}$-CL images indicate a fundamentally different mechanism of flame stabilization for both regimes. While the flame is stabilized through flame propagation in the laminar low velocity regime on the one hand, recirculating hot exhaust gas stabilizes the flame in the turbulent high velocity regime on the other. The latter mechanism is most likely based on permanent autoignition, since autoignition events are visible in the present data. The stabilization based on autoignition can also be the reason of the extraordinary course of the stabilization map for the high velocity regime. 
The extent of the recirculation zone as well as integral turbulent length scales are almost identical for all high velocity regime cases, while the absolute velocities and fluctuation velocities scale nearly proportionally with the jet velocity. This leads to an inversely proportional relation between time scales and jet velocity, which means larger residence times of hot exhaust gas for lower jet velocities. Larger residence times mean a higher heat loss in the recirculation zone and a progressive recombination of radicals in the exhaust gas, both resulting in a less reactive mixture at the jet root. This could be an explanation for the reduced stability of this high velocity regime towards lower velocities. The gap between the two flame stabilization regimes would then correspond to the region where the flow velocities are higher than flame propagation, but too slow to recirculate the reactive exhaust fast enough to sustain autoignition.

This idea has to be confirmed in future experiments: Subsequent laser diagnostic measurements (simultaneous $\mathrm{kHz}$ PIV, OH-PLIF, OH*-CL) and numerical simulations (LES) will be conducted to clarify the role of autoignition and heat loss in the recirculation zone in the high velocity regime. The highly unsteady and three-dimensional nature of the flame in this regime makes these measurements and simulations challenging. The operation point at $v_{\text {jet }}=20 \mathrm{~m} / \mathrm{s}$ and $\lambda=1.0$ has been chosen for these future investigations, since it provides relatively low velocities (resolvable by $\mathrm{kHz}$ diagnostics) and Reynolds numbers (making LES possible), while still being part of the high velocity stabilization regime not too close to the blowoff limit.

\section{References}

\footnotetext{
${ }^{1}$ Lückerath, R., Meier, W., and Aigner, M., "FLOX ${ }^{\circledR}$ Combustion at High Pressure with Different Fuel Compositions," Journal of Engineering for Gas Turbines and Power, Vol. 130, No. 1, 2007, pp. 011505-1-011505-7.

${ }^{2}$ Lammel, O., Schütz, H., Schmitz, G., Lückerath, R., Stöhr, M., Noll, B., Aigner, M., Hase, M., and Krebs, W., "FLOX ${ }^{\circledR}$ Combustion at High Power Density and High Flame Temperatures," Journal of Engineering for Gas Turbines and Power, Vol. 132, No. 12, 2010, pp. 121503ff.

${ }^{3}$ Rödiger, T., Lammel, O., Aigner, M., Beck, C., and Krebs, W., "Part-Load Operation of a Piloted FLOX ${ }^{\circledR}$ Combustion System," Journal of Engineering for Gas Turbines and Power, Vol. 135, No. 3, 2013, pp. 031503-1.

${ }^{4}$ Danon, B., de Jong, W., and Roekaerts, D., "Experimental and Numerical Investigation of a FLOX Combustor Firing Low Calorific Value Gases," Combustion Science and Technology, Vol. 182, No. 9, 2010, pp. 1261-1278.

${ }^{5}$ Gounder, J. D., Zizin, A., Lammel, O., Rachner, M., Kulkarni, S. R., and Aigner, M., "Experimental and numerical investigation of spray characteristics in a new FLOX ${ }^{\circledR}$ based combustor for liquid fuels for Micro Gas Turbine Range Extender (MGT-REX)," 52nd AIAA/SAE/ASEE Joint Propulsion Conference, AIAA Propulsion and Energy Forum, Vol. AIAA 2016$4698,2016$.

${ }^{6}$ Lammel, O., Severin, M., Ax, H., Lückerath, R., Tomasello, A., Emmi, Y., Noll, B., Aigner, M., and Panek, L., "High Momentum Jet Flames at Elevated Pressure, A: Experimental and Numerical Investigation for Different Fuels," ASME Paper no. GT2017-64615, 2017.

7 "FLOX ${ }^{\circledR}$ is a registered trademark of WS Wärmeprozesstechnik GmbH, Renningen, Germany," .

${ }^{8}$ Lammel, O., Stöhr, M., Kutne, P., Dem, C., Meier, W., and Aigner, M., "Experimental Analysis of Confined Jet Flames by Laser Measurement Techniques," Journal of Engineering for Gas Turbines and Power, Vol. 134, No. 4, 2012, pp. $041506-1$.

${ }^{9}$ Wünning, J. A. and Wünning, J. G., "Burners for Flameless Oxidation with Low $\mathrm{NO}_{\mathrm{x}}$ Formation even at Maximum Air Preheat," Gaswärme International, Vol. 41, No. 10, 1992, pp. 438 - 444.

${ }^{10}$ Wünning, J. A. and Wünning, J. G., "Flameless Oxidation to Reduce Thermal NO-Formation," Prog. Energy Combust. Sci., Vol. 23, 1997, pp. $81-94$.

${ }^{11}$ Cavaliere, A. and Joannon, M., "Mild Combustion," Prog. Energy Comb. Sci., Vol. 30, 2004, pp. 329 - 366.

${ }^{12}$ Lammel, O., Severin, M., Ax, H., and Lückerath, R., "FLOX Wobbe: Entwicklung von Brennstoffdüsen für erweiterte Brennstoffflexibilität : Charakterisierung des Verbrennungssystems im Labormaßstab: Verbundprojekt Siemens Clean Energy Center - Entwicklung von Verbrennungstechnologien für die klimaschonende Energieerzeugung, Teilprojekt 1.4/1D," Project Report. DOI: 10.2314 / GBV:881235768, 2017.

${ }^{13}$ Melling, A., "Tracer particles and seeding for particle image velocimetry," Meas. Sci. Technol., Vol. 8, 1997, pp. 14061416.

${ }^{14}$ Wohl, K., Kapp, N. M., and Gazley, C., "The Stability of Open Flames," Proc. Combust. Inst., Vol. 3, 1949, pp. 3-40.

${ }^{15}$ Law, C. K., Combustion Physics, Cambridge University Press, 2006.

${ }^{16}$ Lefebvre, A. H. and Ballal, D. R., Gas Turbine Combustion, 3rd ed., CRC Press, Taylor\&Francis Group, 2010.

${ }^{17}$ Seliger, H., Huber, A., and Aigner, M., "Experimental investigation of a FLOX ${ }^{\circledR}$-based combustor for a small-scale gas turbine based CHP system under atmospheric conditions," ASME paper no. GT2015-43094, 2015.

${ }^{18}$ Avila, M., Willis, A. P., and Hof, B., "On the transient nature of localized pipe flow turbulence," J. of Fluid Mech., Vol. 646, 2010, pp. $127-136$.

${ }^{19}$ Barkley, D., "Simplifying the complexity of pipe flow," Phys. Rev. E, Vol. 84, No. 016309, 2011.

${ }^{20}$ Avila, K., Moxey, D., de Lozar, A., Avila, M., Barkley, D., and Hof, B., "The Onset of Turbulence in Pipe Flow," Science, Vol. 333, No. 6039, 2011, pp. 192-196.

${ }^{21}$ Reynolds, O., "An Experimental Investigation of the Circumstances which Determine Whether the Motion of Water Shall Be Direct or Sinuous, and of the Law of Resistance in Parallel Channels," Philos. Trans. R. Soc. London A, Vol. 174, No. 935, 1883.
} 
${ }^{22}$ Yin, Z., Boxx, I., Stöhr, M., Lammel, O., and Meier, W., "Confinement-Induced Instabilities in a Jet-Stabilized Gas Turbine Model Combustor," Flow Turbulence and Combustion, Vol. 98, 2016, pp. 217-235.

${ }^{23}$ Navarro-Martinez, S. and Kronenburg, A., "LES-CMC simulations of a lifted methane flame," Proc. Combust. Inst., Vol. 32, 2009, pp. 1509-1516.

${ }^{24}$ Yoo, C. S., Richardson, E. S., Sankaran, R., and Chen, J. H., "A DNS study on the stabilization mechanism of a turbulent lifted ethylene jet flame in highly-heated coflow," Proc. Combust. Inst., Vol. 33, 2011, pp. 1619-1627.

${ }^{25}$ Smith, G. P., Golden, D. M., Frenklach, M., Moriarty, N. W., Eiteneer, B., Goldenberg, M., Bowman, C. T., Hanson, R. K., Song, S., Jr., W. C. G., Lissianski, V. V., and Qin, Z., "GRI-MECH 3.0," http://www.me.berkeley.edu/gri_mech/.

${ }^{26}$ Pope, S. B., Turbulent Flows, Cambridge University Press, 2000.

${ }^{27}$ Borghi, R. W., "On the Structure and Morphology of Turbulent Premixed Flames," Recent Advances in the Aerospace Science, 1985, pp. 117-138.

${ }^{28}$ Peters, N., Turbulent Combustion, Cambridge University Press, 2000. 